\title{
Minimally invasive treatment of spinal dural arteriovenous fistula with the use of intraoperative indocyanine green angiography
}

\author{
Ricardo B. Fontes, M.D., Ph.D., Lee A. Tan, M.D., and John E. O’Toole, M.D. \\ Department of Neurosurgery, Rush University Medical Center, Chicago, Illinois
}

\begin{abstract}
Spinal dural arteriovenous fistula (dAVF) is the most common vascular malformation of the spinal cord. Traditionally it is treated by the standard muscle-splitting midline approach with bilateral laminectomies extending from one level above to one level below the dAVF. We present a minimally invasive approach for ligation of dAVF with concurrent use of intraoperative indocyanine green (ICG) angiography. Minimally invasive watertight dural closure technique is also demonstrated and discussed. The minimally invasive approach with intraoperative ICG results in quicker recovery, early mobilization and shorter hospital stay compared to traditional open approach.
\end{abstract}

The video can be found here: http://youtu.be/mNUeJKLxL3Q.

(http://thejns.org/doi/abs/10.3171/2013.V2.FOCUS13191)

KEY WoRDS $\stackrel{\text { minimally invasive }}{\bullet}$ spinal dural AVF $\quad$ indocyanine green
ICG $\bullet$ durotomy closure $\bullet \quad$ video

Manuscript submitted April 27, 2013.

Accepted May 30, 2013.

Please include this information when citing this paper: DOI: 10.3171/2013.V2.FOCUS13191.

Address correspondence to: Lee A. Tan, M.D., Department of Neurosurgery, Rush University Medical Center, 1725 W. Harrison Street, Suite 855, Chicago, IL 60612. email: lee_tan@rush.edu. 